\title{
A Study of Paediatric Supracondylar Fractures of the Humerus Presented During the COVID-19 Pandemic
}

\author{
By Faaiz Ali Shah ${ }^{*}$ Mian Amjad Ali ${ }^{ \pm}$Naeemullah ${ }^{*}$ \& \\ Muhammad Bilal ${ }^{\text {s }}$
}

\begin{abstract}
Supracondylar fracture of the humerus is one of the most common fractures in children. The purpose of our study was to analyze the temporal variations and mechanisms of paediatric supracondylar fractures presented to our hospital during the COVID-19 pandemic lockdown period. As the schools and parks were closed and children were confined to their homes, they were thus more prone to injuries while playing inside. We claim that this would be the first study in Pakistan to provide unique information about these fractures. We conducted this descriptive study in the Accident and Emergency Department at Lady Reading Hospital in Peshawar, Pakistan from $18^{\text {th }}$ March 2020 to $18^{\text {th }}$ June 2020. In the enrolled children data regarding day and time of fracture occurrence, mechanism of fracture, height of furniture or play equipment from which the children fall and types of landing surfaces were all noted. Important variables were compared and a Chi-square test was applied to calculate $P$ value $(P<0.05$ was considered significant). The total number of children in our study was 160 with a mean age of $5.3 \pm 1.3$ years. The most common mechanism of fracture was fall from furniture $(63.1 \%, n=101)$ and the landing surface was cemented or tiled floor in the majority (84.1\%, $n=101)$ of children. Maximum $(40.6 \%, n=65)$ number of fractures were reported in the month of April and on a Monday (23.7\%, $n=38)$. Most (65.6\%, $n=105)$ children sustained fractures in PM time. The peak time of occurrence of fracture was $1700 \mathrm{~h}$. We concluded that the majority of children sustained fractures due to a fall from furniture landing on hard cemented or tiled surfaces. Maximum number of fractures was reported in the month of April and on a Monday. Most of these injuries occurred in the evening and were operated on at night. The increased frequency of paediatric supracondylar fractures in the COVID-19 pandemic supports that preventative strategies should focus more on adult supervision, prevention of falls from furniture and provision of softer landing surfaces to lessen the impact of injury.
\end{abstract}

Keywords: fracture, gartland, humerus, paediatric, supracondylar, surface resilience, temporal variations, weekday

\section{Introduction}

Paediatric supracondylar humerus fractures are the most common elbow fractures and account for 12 to $17 \%$ of all bone fractures in children (Mangwani et al. 2006, Mulpuri et al. 2012, Wareham et al. 2003). Male children in their first decade, particularly between 5 to 8 years of age with left-side involvement are the

\footnotetext{
*Assistant Professor, Orthopaedics \& Traumatology Division, Lady Reading Hospital Peshawar, Pakistan.

${ }^{ \pm}$Professor, Orthopaedics \& Traumatology Division, Lady Reading Hospital Peshawar, Pakistan.

"Assistant Professor, Orthopaedics \& Traumatology Division, Lady Reading Hospital Peshawar, Pakistan.

${ }^{\S}$ Post Graduate Resident, Orthopaedics \& Traumatology Division, Lady Reading Hospital Peshawar, Pakistan.
} 
typical representation of supracondylar humerus fractures (Della-Giustina and Della-Giustina 1999, Marquis et al. 2008). Managing these fractures is costly because they often require admission to hospital and surgical intervention (Loder et al. 2012). Displaced supracondylar fractures are treated with close reduction and percutaneous pinning (CRPP) under an image intensifier (Mulpuri et al. 2012, Omid et al. 2008, Woratanarat et al. 2012). Open reduction and pinning is utilized when the fracture is open, with an associated vascular injury or the closed method is failed (Mulpuri et al. 2012, Omid et al. 2008, Woratanarat et al. 2012, Babal et al. 2010). Although variations in the demographic characteristics such as age, gender and side of supracondylar fractures have been reported by many studies, the temporal characteristics (month of injury, day of the week and hour of the day) of this fracture, particularly in our region, has not yet been studied (Loder et al. 2012, Babal et al. 2010, McRae and Nusem 2018). The first two confirmed deaths due to COVID-19 occurred in Pakistan on $18^{\text {th }}$ March 2020 and both the patients were admitted in our hospital, Lady Reading Hospital Peshawar Pakistan (Latif 2020). Following an increased influx of COVID-19 patients to our hospitals, the government of Pakistan declared a health emergency and announced strict lockdown for an indefinite time period. We had been receiving an increasing number of children with supracondylar humerus fractures daily during the COVID-19 pandemic lockdown in Lady Reading Hospital in Peshawar, Pakistan. This was due to the fact that children were entirely confined to their homes and were more prone to injury during play time in a limited and unsafe environment. Furthermore, as peripheral and district level healthcare services and private clinics had been closed temporarily by the government, children were referred to our hospital as our hospital is the largest tertiary care teaching hospital of this province.

The objective of our study was to determine the temporal variations and mechanism of injury of supracondylar humerus fractures presented to the Accident and Emergency Department (A\&E) at Lady Reading Hospital in Peshawar, Pakistan during the COVID-19 pandemic lockdown. We claimed that our study was the first study on this topic in our country. The results of this study will be used to anticipate the day of the week and hour of the day of arrival of supracondylar fractures to A\&E. This will help us in prompt allocation of adequate resources in the form of dedicated paediatric orthopaedic surgeons, operation theatres and supporting staff without affecting regular surgical work. Furthermore, knowledge of the exact mechanism of these fractures will help us to improve the safety profile of children's playing environment inside home.

\section{Methods}

This descriptive study was conducted in the Accident and Emergency Department at Lady Reading Hospital in Peshawar, Pakistan. The duration of our study extended from the COVID-19 pandemic lockdown from $18^{\text {th }}$ March 2020 ("Strict Lockdown") until $18^{\text {th }}$ June 2020 when relaxation in the lockdown ("Smart Lockdown") was allowed and partial elective hospital services of our hospital 
were resumed. The questionnaire and methodology for this study was approved by the Ethical Review Board (ERB) at Lady Reading Hospital in Peshawar, Pakistan. The principal investigator has obtained a Good Clinical Practice Certificate from the National Institute on Drug Abuse (NIDA), Center for Clinical Trials (CCTN) and Clinical Trials Network (CTN) and has ORCID ID: http://orcid.org/0000-00 01-7894-0340. Children of either gender and age up to 12 years with supracondylar fractures received in A \& E department within 3 days after sustaining the fracture were included in the sample. Children operated upon in other hospitals were excluded. The sample size for the study was 160 and calculated with the help of formula $n=Z^{2} P(1-P) / d^{2}$, whereas $n=$ Sample size, $Z=$ level of confidence $(95 \%$ or 1.96), $\mathrm{P}=$ prevalence (0.12) (Mangwani et al. 2006) and $\mathrm{d}=$ Precision (5\% or 0.05). All children of supracondylar fractures received in the Accidents and Emergency Department of Lady Reading Hospital in Peshawar were thoroughly assessed and resuscitated according to ATLS protocols. The children were given analgesics for pain relief and the fractures were splinted. Radiographs of the elbow joint anteroposterior and lateral views were done and fractures were classified according to the Gartland classification system (Gartland 1959).

Distal neurovascular status was documented. Patients of supracondylar fractures meeting the inclusion criteria were admitted and operated as per hospital protocol. For the included children, a complete history and physical examination was done and informed written consent was taken from parents. All children with Gartland type-I fractures were treated in splint, while type-II and III were treated with closed reduction/percutaneous pinning under image intensifier or open reduction and pinning as required. Temporal variations or day and time of fracture occurrence, exact details of fracture mechanism, height of furniture or equipment from which the child fell and the type of landing surfaces were inquired from parents of each and every child and recorded. For convenience we divided the fracture mechanisms into six categories (Okubo et al. 2019) as follows:

I) Tumble, on outstretched elbow at ground level while playing and running.

II) Fall, on outstretched elbow from above ground level (climbing, bicycle, chair, bed, table, stairs etc.)

III) Lateral bend, the elbow during sports or accidents

IV)Direct hit, smashed by an object or the elbow got caught in the door.

V) Throw, injured after throwing a ball or other object.

VI)Unknown.

Statistical analysis of our data was done by using SPSS version 20. Categorical variables like gender and fracture side was represented as frequency and percentage while mean \pm SD was calculated for numerical variables like age. A comparison of important variables like day and time of occurrence of supracondylar fractures, heights of furniture and landing or impact surfaces were done and Chi-square test was applied to calculate the $\mathrm{P}$ value. $\mathrm{P}$ value $<0.05$ was considered statistically significant. Results were presented in tables where necessary. 


\section{Results}

The total number of children in our study was 160 . Boys were $121(75.6 \%)$ and girls were $39(24.3 \%)$. Mean age of our patients were $5.3 \pm 1.3$ years (range 3 to 9 years). Right supracondylar was fractured in $26(16.2 \%)$ and left in 134 $(83.7 \%)$. Bilateral fractures were not reported in our series. Supracondylar humerus fractures were associated with clavicle fractures in $8(5 \%)$ children, proximal humerus fractures in $6(3.7 \%)$ children and distal radius fractures in $5(3.1 \%)$ children. Majority $(80 \%, \mathrm{n}=128)$ children were received in our hospital within 24 hours of sustaining the fracture, while $28(17.7 \%)$ in 24 to 48 hours and $4(2.5 \%)$ children were received within 48 to 72 hours of sustaining the fracture. Delayed presented children $(2.5 \%, \mathrm{n}=4)$ were initially treated with splints by traditional bone setters. Radiologically, all fractures were of extension types with Gartland type I fracture in 28 (17.5\%) children, type II in 27 (16.8\%) and type III in 105 $(65.6 \%)$ children. The mechanism of fracture in the majority $(75.6 \%, \mathrm{n}=121)$ of children was due to a fall from height and $101(63.1 \%)$ children had fracture due to a fall from furniture inside the home (Table 1). Overall, $138(86.2 \%)$ children sustained fractures indoors while $22(13.7 \%)$ children sustained fracture outside of the home on a nearby street. Majority $(40.6 \%, \mathrm{n}=65)$ of fractures were reported in the month of April followed by May $(25 \%, \mathrm{n}=40)$, June $(21.2 \%, \mathrm{n}=35)$ and March $(12.5 \%, \mathrm{n}=20)$. We noted that children sustained fractures more on Monday $(23.7 \%, \mathrm{n}=38)$ and Friday $(19.3 \%, \mathrm{n}=31)$ than on other weekdays $(\mathrm{P}>0.05)$ as shown in Table 2. Most $(65.6 \%, \mathrm{n}=105)$ children sustained fractures in PM while $55(34.3 \%)$ children had fractures in AM. The peak time of occurrence of fracture was $1700 \mathrm{~h}$ and majority $(86.2 \%, \mathrm{n}=138)$ children were received in our hospital in 1800-2000 hr.

We identified four impact-absorbing surfaces beneath the furniture or play equipment on which the children landed after a fall from height and sustained fractures. These surfaces were carpet or mattress, cemented or tiled floor, grass and mud or sand (Table 3). Majority $(88.4 \%, n=84 / 95)$ of children falling from height onto a cemented or tiled floor sustained Gartland type III fractures than other types $(\mathrm{P}<0.05)$, while only 1 out of $13(7.6 \%)$ children got type III fracture $(\mathrm{P}<0.05)$ falling on mud or sand. Similarly, no type III fracture was noted in children who landed on a mud or sand surface after falling on an outstretched elbow at ground level $(\mathrm{P}<0.05)$.

The analysis of height of furniture or playing equipment revealed that the average height was $4.3 \pm 2$ feet (range 2.6 to 6 feet). A total of $55(45.4 \%)$ children falling from a height of up to 4 feet had Gartland type III fractures, while 66 $(54.5 \%)$ children sustained a type III fracture had fallen from a height of above 4 feet $(\mathrm{P}>0.05)$.

Majority $(89.3 \%, \mathrm{n}=143)$ of the fractures were closed while $17(10.6 \%)$ children had open fractures. All the children were managed appropriately as per protocol. Closed reduction and percutaneous pinning under image intensifier was done in $92(87.6 \%)$ children with type III fractures, while open reduction and stabilization with $\mathrm{k}$ wires in $13(12.3 \%)$ children were done after failed attempts of closed reduction. Gartland type I fractures $(17.5 \%, n=28)$ were treated with 
immobilization in a splint while type II fractures $(16.8 \%, \mathrm{n}=27)$ were treated with closed reduction and splinting. Pre-operative anterior interosseous nerve injury was noted in $4(2.5 \%)$ patients while post-operative ulnar nerve injury was documented in $7(4.3 \%)$ patients.

Table 1. Aetiology and Classification of Supracondylar Fractures in Children

\begin{tabular}{|c|c|c|c|c|c|c|c|}
\hline \multirow[t]{2}{*}{ S.No } & \multirow{2}{*}{\multicolumn{2}{|c|}{ Mechanism of Fracture }} & \multirow{2}{*}{$\begin{array}{l}\text { Number of } \\
\text { children }\end{array}$} & \multirow[t]{2}{*}{ Percentage } & \multicolumn{3}{|c|}{$\begin{array}{c}\text { Number of Gartland } \\
\text { fractures }(n=160)\end{array}$} \\
\hline & & & & & $\begin{array}{c}\text { Type } \\
\text { I }\end{array}$ & $\begin{array}{c}\text { Type } \\
\text { II }\end{array}$ & $\begin{array}{c}\text { Type } \\
\text { III }\end{array}$ \\
\hline 1 & \multicolumn{2}{|c|}{ Tumble } & 26 & $16.2 \%$ & 12 & 11 & 03 \\
\hline \multirow{4}{*}{2} & \multirow{4}{*}{ Fall } & $\begin{array}{c}\text { From } \\
\text { Furniture }\end{array}$ & 101 & $63.1 \%$ & 04 & 8 & 89 \\
\hline & & From Bicycle & 11 & $6.8 \%$ & 01 & 04 & 06 \\
\hline & & From Stairs & 5 & $3.1 \%$ & 00 & 01 & 04 \\
\hline & & From tree & 4 & $2.5 \%$ & 00 & 01 & 03 \\
\hline 3 & \multicolumn{2}{|c|}{ Lateral Bend } & 3 & $1.8 \%$ & 03 & 00 & 00 \\
\hline 4 & \multicolumn{2}{|c|}{ Direct Hit } & 5 & $3.1 \%$ & 04 & 01 & 00 \\
\hline 5 & \multicolumn{2}{|c|}{ Throw } & 2 & $1.2 \%$ & 02 & 00 & 00 \\
\hline 6 & \multicolumn{2}{|c|}{ Unknown } & 3 & $1.8 \%$ & 02 & 01 & 00 \\
\hline
\end{tabular}

Table 2. Day and Time of Supracondylar fractures of Humerus in Children

\begin{tabular}{|c|c|c|c|c|c|c|c|c|c|c|}
\hline \multirow{2}{*}{ S.No } & \multirow{2}{*}{$\begin{array}{l}\text { Day of } \\
\text { Injury }\end{array}$} & \multirow{2}{*}{$\begin{array}{l}\text { Number } \\
\text { of } \\
\text { fractures }\end{array}$} & \multirow{2}{*}{ Percentage } & \multirow{2}{*}{$\mathbf{A M}$} & \multirow{2}{*}{$\mathbf{P M}$} & \multirow{2}{*}{$\begin{array}{c}P \\
\text { value }\end{array}$} & \multicolumn{3}{|c|}{ Time of Injury } & \multirow[b]{2}{*}{$\begin{array}{c}P \\
\text { Value }\end{array}$} \\
\hline & & & & & & & $\begin{array}{c}0000- \\
1159 \\
\end{array}$ & $\begin{array}{l}1200- \\
1559 \\
\end{array}$ & $\begin{array}{l}1600- \\
2359 \\
\end{array}$ & \\
\hline 1 & Monday & 38 & $23.7 \%$ & 14 & 24 & 0.2 & 14 & 10 & 14 & 0.6 \\
\hline 2 & Tuesday & 21 & $13.1 \%$ & 07 & 14 & 0.3 & 07 & 04 & 10 & 0.3 \\
\hline 3 & Wednesday & 18 & $11.2 \%$ & 07 & 11 & 0.4 & 07 & 03 & 08 & 0.2 \\
\hline 4 & Thursday & 22 & $13.7 \%$ & 06 & 16 & 0.3 & 06 & 07 & 09 & 0.4 \\
\hline 5 & Friday & 31 & $19.3 \%$ & 10 & 21 & 0.2 & 10 & 11 & 10 & 0.1 \\
\hline 6 & Saturday & 17 & $10.6 \%$ & 06 & 11 & 0.3 & 06 & 03 & 08 & 0.3 \\
\hline 7 & Sunday & 13 & $8.1 \%$ & 05 & 08 & 0.4 & 05 & 02 & 06 & 0.2 \\
\hline
\end{tabular}

Table 3. Frequency of Different Supracondylar Fractures Sustained on Different Landing Surfaces

\begin{tabular}{|c|c|c|c|c|c|c|c|c|c|c|c|c|c|c|}
\hline \multirow{3}{*}{\multicolumn{2}{|c|}{ Aetiology }} & \multicolumn{12}{|c|}{ Landing Surfaces } & \multirow[b]{3}{*}{$\begin{array}{c}\text { Total } \\
(\mathrm{n}=147)\end{array}$} \\
\hline & & \multicolumn{3}{|c|}{ Carpet/Mattress } & \multicolumn{3}{|c|}{ Cemented/Tiled Floor } & \multicolumn{3}{|c|}{ Grass } & \multicolumn{3}{|c|}{ Mud/Sand } & \\
\hline & & $\begin{array}{c}\text { Type } \\
\text { I } \\
\end{array}$ & $\begin{array}{c}\text { Type } \\
\text { II }\end{array}$ & $\begin{array}{c}\text { Type } \\
\text { III }\end{array}$ & $\begin{array}{c}\text { Type } \\
\text { I }\end{array}$ & $\begin{array}{c}\text { Type } \\
\text { II }\end{array}$ & $\begin{array}{c}\text { Type } \\
\text { III }\end{array}$ & $\begin{array}{c}\text { Type } \\
\text { I }\end{array}$ & $\begin{array}{c}\text { Type } \\
\text { II }\end{array}$ & $\begin{array}{c}\text { Type } \\
\text { III }\end{array}$ & $\begin{array}{c}\text { Type } \\
\text { I } \\
\end{array}$ & $\begin{array}{c}\text { Type } \\
\text { II }\end{array}$ & $\begin{array}{c}\text { Type } \\
\text { III } \\
\end{array}$ & \\
\hline \multicolumn{2}{|c|}{ Tumble } & 01 & 02 & 01 & 01 & 04 & 01 & 01 & 03 & 01 & 09 & 02 & 00 & $\begin{array}{c}26 \\
(17.6 \%)\end{array}$ \\
\hline \multirow{4}{*}{ Fall } & Furniture & 02 & 03 & 13 & 02 & 05 & 76 & 00 & 00 & 00 & 00 & 00 & 00 & $\begin{array}{c}101 \\
(68.7 \%) \\
\end{array}$ \\
\hline & Bicycle & 00 & 00 & 00 & 01 & 02 & 04 & 00 & 01 & 01 & 00 & 01 & 01 & $\begin{array}{c}11 \\
(7.4 \%) \\
\end{array}$ \\
\hline & Stairs & 00 & 00 & 00 & 00 & 00 & 02 & 00 & 01 & 02 & 00 & 00 & 00 & $\begin{array}{c}05 \\
(3.4 \%)\end{array}$ \\
\hline & Tree & 00 & 00 & 00 & 00 & 01 & 02 & 00 & 0 & 01 & 00 & 00 & 00 & $\begin{array}{c}04 \\
(2.7 \%)\end{array}$ \\
\hline \multicolumn{2}{|c|}{ Total } & 03 & 05 & 14 & 04 & 12 & 85 & 01 & 05 & 05 & 09 & 03 & 01 & 147 \\
\hline
\end{tabular}




\section{Discussion}

Due to the COVID-19 outbreak, the government of Pakistan strictly instructed the public to stay inside their homes. As a result children were confined to homes. This was reflected from the findings of our study as the majority $(86.2 \%, \mathrm{n}=136)$ of our children sustained fractures indoors, while only few children $(13.7 \%, \mathrm{n}=22)$ sustained fracture outside home on a nearby street. In an epidemiological analysis of 488 paediatric elbow fractures, Okubo et al. (2019) reported that supracondylar fractures were the most common $(43.8 \%, \mathrm{n}=214)$, followed by lateral condyle fractures $(22.3 \%, \mathrm{n}=109)$. Overall the most common cause of fracture in this study were also indoor falls noted in $242(49.5 \%)$ children with indoor causes, such as falls from a chair in $18(3.6 \%)$ children, sofas in $11(2.2 \%)$ and beds in $6(1.2 \%)$ children. Outdoor falls from playground equipment were responsible for fractures in $14(2.8 \%)$ children, with falls from trees in $11(2.2 \%)$, iron rods in $11(2.2 \%)$ and aerial ladders in $10(2 \%)$ children. Analysis of other fracture mechanisms revealed that tumbles had caused fractures in $214(43.8 \%)$ children, lateral bends in $9(1.8 \%)$, direct hits in $11(2.2 \%)$, throws in $10(2 \%)$ and unknown mechanisms in $10(2 \%)$ children. These authors, however, narrated that this aetiology was not for supracondylar fractures alone, but for all paediatric elbow fractures. Furthermore, the frequency of fractures were highest in May $(11.4 \%, n=56)$ and August $(5.1 \%, \mathrm{n}=25)$ in comparison to our study where we had noted highest frequency of supracondylar fractures in April $(40.6 \%, \mathrm{n}=65)$ and May $(25 \%$, $\mathrm{n}=40$ ). These authors concluded that the frequency of paediatric elbow fractures could not be attributed to environmental temperature only because there were many other factors which could influence fracture rate, namely urban/rural setting, culture and holidays. Sinikumpu et al. (2017) and Khoshbin et al. (2014) also reported the peak incidence of supracondylar fractures in summer because children preferred to play in warm than in cold environments. Loder et al. (2012) documented 48 (13.5\%) supracondylar fractures in the month of June, $46(13 \%)$ in May, $30(8.4 \%)$ in March and $27(7.6 \%)$ in April. Seasonal variations of supracondylar fractures are important to understand in regions where great climate variations exist because effective resource utilization and cost planning can be improved.

In our study, right supracondylar was fractured in $26(16.2 \%)$ and left in 134 (83.7\%) children. This finding was similar to the studies of Loder et al. (2012) and Babal et al. (2010). The most likely explanation could be the possibility of dominant upper limb in use during play while the non-dominant hand assumed the position of protection during fall or injury.We considered this finding important because most $(91 \%, n=123)$ children in our series were right-handed and parents could expect ease in feeding, dressing and ability to accomplish written school homework in these children.

Days and time analysis of our fracture data showed that children sustained fractures more on Monday $(23.7 \%, \mathrm{n}=38)$ and Friday $(19.3 \%, \mathrm{n}=31)$ than on other week days $(\mathrm{P}>0.05)$. Majority $(65.6 \%, \mathrm{n}=105)$ of the children were injured in PM while $55(34.3 \%)$ in AM. The peak time of occurrence of fracture was $1700 \mathrm{~h}$ and most $(86.2 \%, \mathrm{n}=138)$ children were received in our hospital in 1800-2000 hr. It 
could be expected that since majority of these children would be operated at night and dedicated orthopaedic surgeons and efficient operating theatre staff would be of paramount importance. Somewhat similar to our study, Loder et al. (2012) noted that children sustained fractures more on Saturday $(17.2 \%, \mathrm{n}=61)$ and Friday $(17.2 \%, \mathrm{n}=61)$, followed by Tuesday $(14.4 \%, \mathrm{n}=51)$ and Monday $(13.5 \%, 48)$. He documented that maximum fractures $(68.2 \%, \mathrm{n}=241)$ occurred in PM while 37 (10.4\%) fractures occurred in AM. The peak time of fracture was $1800 \mathrm{~h}$ in his study. Chai et al. (2000) noted male predominance of supracondylar fractures in his series with majority sustained inside home and peak time of occurrence of majority fractures were at 1800 . McRae and Nusem (2018) examined the clinical record of 569 patients who were treated for supracondylar fractures between 2004 and 2014. Most of the fractures were presented to the hospital around 1700-17:59 h. In our study the analysis of landing surfaces after fall and height of furniture or play equipment revealed that the frequency of type III fractures were more in children landing on cemented or tiled surfaces $(\mathrm{P}<0.05)$. The frequency was lower, however, on mud or sand landing surfaces $(\mathrm{P}<0.05)$. No significant increased frequency of type III fracture was noted in children falling from a height of 3 or more feet $(\mathrm{P}>0.05)$. Many authors studied the impact of surface characteristics and height of play equipment or furniture on the incidence of supracondylar fractures in children. Laforest el al. (2001) showed that children falling from equipment with a height greater than 2-meters sustained injuries 2.6 times more than those falling from a lesser height. Furthermore, he advocated that the resilience of the surface (represented by surface hardness and measured as ratio of maximum negative acceleration on impact in units of gravities to the acceleration due to gravity, Gmax) on which children fall should be less than $200 \mathrm{~g}$ to reduce the incidence of injuries. They advised that sand should be used beneath the equipment as it reduces the severity of injuries. In an earlier study, Laforest el al. (2000) analyzed the data of 930 injured children and found that most children sustained injuries at home rather than at public playgrounds. He observed that $698(75 \%)$ fractures were sustained when children fall down on grass while 232 (24.9\%) fractures were sustained on sand beneath the play equipment. The author claimed that his study was the first epidemiological study to prove that grass was not a good protective surface beneath playing equipment. He therefore recommended that grass should be replaced by sand beneath playing equipment. Barr (2014) analyzed the data of supracondylar fractures in children over a 3 year period at a district general hospital. He documented that these injuries were more common during summer school holidays. Playground equipment was responsible for $38 \%$ of fractures while falls from furniture had caused fractures in $16 \%$ children in his series. Barr advised that since children could not be stopped from playing, only preventative strategies could be adopted to make playing areas safer. Lowering the height of play equipment, application of softer landing surface beneath the furniture or equipment and play supervision by parents or adults would be expected to reduce the incidence of supracondylar fractures. Barr's safety and preventative measures were endorsed by Park et al. (2010).

Gartland type III was the predominant type $(65.6 \%, \mathrm{n}=105)$ of fracture noted in our study. This was consistent with the studies of Cheng et al. (2001) and 
Mangwani et al. (2006), but in contrast to Houshian et al. (2001). Houshian et al. reported type I to be the predominant type of fracture and the possible reasons he stated was either low-energy trauma in his series or increased sensitivity of radiographs to detect undisplaced supracondylar fractures. Fiissel et al. (2005) was of the opinion that minor fractures in children were caused by falls from standing heights, while major fractures were caused by falls from height and 3.9 times more likely required reductions. Our study participants had a mean age of $5.3 \pm 1.3$ years (range 3 to 9 years) and the majority $(86.2 \%, n=138)$ of children sustained fractures at home. Striano et al. (2020) assessed the differences in epidemiology of Gartland type III fractures in 94 toddlers with a mean age of $2.11 \pm 0.64$ years and 378 older children with a mean age of $6.32 \pm 1.89$ years. These authors revealed that toddlers sustained fractures at home due to non-accidental causes while older children had more associated injuries often requiring open reduction. Loss of fracture reduction and cubitus varus was more frequent in toddlers than in older children. These authors advocated age-specific management of type III fractures.

In our study pre-operative anterior interosseous nerve injury was present in 4 (2.5\%) patients while post-operative ulnar nerve injury was noted in $7(4.3 \%)$ patients. A study of Khademolhosseini et al. (2013) of 272 children in Malaysia, reported pre-operative nerve injury in $9(3 \%)$ children and post-operative ulnar nerve injury in $34(12.5 \%)$ children, radial nerve in $3(1.1 \%)$ and median nerve injury in $2(0.7 \%)$ children. Barr (2014) noted nerve injury in $3(3.5 \%)$ children upon presentation while post-operative neurological compromise was reported in 2 $(0.7 \%)$ children in his series of 84 supracondylar distal humerus fractures of extension type. In a meta-analysis by Babal et al. (2010) the data of 5,154 supracondylar fractures revealed that pre-operative anterior interosseous injuries were present in $34.1 \%$ children. Post-operative iatrogenic ulnar nerve injury was noted in $4.1 \%$ and median nerve injury in $3.4 \%$ children. Babal was of the opinion that lateral pinning was associated with more chances of median nerve injury whereas ulnar nerve injury was more frequently seen with medial pinning. Mangwani et al. (2006) shared their ten year experience (1993-2003) of 291 supracondylar fractures and noted neurological deficit in $12(4.1 \%)$ children on presentation and 9 (3\%) children post-operatively. Canales-Zamora et al. (2020) analyzed the data of 277 children under 8 years of age and noted equal frequency of both pre-operative and post-operative neurological injury (1.44\% each). LiBrizzi et al. (2020) documented an overall pre-operative neurological injury in $117(9.5 \%)$ children out of his series of 1,231 supracondylar fractures. The anterior interosseous nerve injury was noted in $43(36.75 \%)$ children. LiBrizzi noted a higher association of older age of children, high energy trauma and Gartland type III fractures with increased frequency of neurological injuries. Aparicio et al. (2019) reported that the frequency of neurological injuries were $(6.4 \%, n=9)$ out of 140 children in his series.

In our study the peak time of occurrence of fracture was $1700 \mathrm{~h}$ and majority $(86.2 \%, \mathrm{n}=138)$ of children were received in our hospital in 1800-2000 hrs and were operated on at night. Although Ricci et al. (2009) reported adverse outcome with delaying surgical management of orthopaedic cases, on the contrary others such as Mehlman et al. (2001), Gupta et al. (2004), Sibinski et al. (2006), Iyengar 
et al. (1999) reported that delaying surgery of a supracondylar fracture did not affect the outcome significantly.

The incidence of supracondylar fractures and its surgical treatment is on the rise globally (Helenius et al. 2009, Salonen et al. 2013, Sinikumpu et al. 2016). Irrespective of any type of treatment, long-term morbidity had been reported in $25 \%$ of children with supracondylar fractures (Sinikumpu et al 2016). The preventive measures are thus justified and must focus on environmental, biological and behavioral factors and our study aids in understanding these factors. Paediatric injury rates and severity due to hazards of equipment can be reduced significantly when optimal safe equipment height and landing surfaces are maintained (Sacks et al. 1992, Roseveare et al. 1999, Howard et al. 2005).

In this study $92(87.6 \%)$ type III fractures were treated with closed reduction and percutaneous pinning under image intensifier, while open reduction and $\mathrm{k}$ wires fixation was done in $13(12.3 \%)$ children after failed attempts of closed reduction. Khoshbin et al. (2014) reported $78.7 \%$ closed reduction and k wire fixation and $21.3 \%$ open reduction and $\mathrm{k}$ wire fixation in their series of 3,235 supracondylar fractures. Other studies documented conversion rates of percutaneous to open surgery in $22.4 \%$ to $47.2 \%$ cases (Aktekin et al. 2008, Turhan et al. 2008, Mazda et al. 2001). This debate of closed versus open surgery is important due to the fact that some previous studies had reported decreased range of elbow motion and increased carrying angle when supracondylar fractures were treated with open reduction rather than closed reduction and percutaneous $\mathrm{k}$ wire fixation (Ozkoc et al. 2004, Cramer et al. 1992).

In our study we were unable to document the exact nutritional status of children, but it is important because good nutritional status and adequate calcium and vitamin $\mathrm{D}$ have been shown to increase bone mineral mass and are protective against fractures in children (Bianchi 2007). Furthermore low socioeconomic status and excessive consumption of carbonated drinks have also been shown to increase the risk of fractures in children (Goulding 2007, Hallal et al. 2009). Majority of our study participants were, although poor, apparently healthy and without any genetic disorders or chronic debilitating diseases.

In literature, vascular injuries have been reported with supracondylar fractures particularly in Gartland type III fractures (Ottolenghi 1956, Campbell et al. 1995), but luckily we have not noted any vascular injury in our series. Supracondylar fractures due to child abuse, although reported in up to $20 \%$ of cases in literature, had not been noted in our series (Strait et al. 1995).

In our series, the majority $(75.6 \%, \mathrm{n}=121)$ of study participants were boys while girls were 39 (24.3\%). This is in accordance with the study of Anjum et al. (2017). However, few other studies had documented no significant difference in the incidence of supracondylar fractures among boys and girls - rather, a higher incidence noted in girls (Lee et al. 2007, Milbrandt and Copley 2004).

About $17(10.6 \%)$ children had open supracondylar fractures in our study. This was slightly higher than reported in previous studies where $1 \%$ to $3.4 \%$ of children had been reported to have open supracondylar fractures (Anjum et al. 2017, Skaggs and Flynn 2010). 
We noted that $18(11.2 \%)$ children had associated injuries along with supracondylar fractures. These injuries included clavicle fractures in $8(5 \%)$, proximal humerus fractures in $6(3.7 \%)$ and physeal injury to distal radius in 5 (3.1\%) children. Other studies (Anjum et al. 2017, Skaggs and Flynn 2010, Cheng et al. 2001, Roposch et al. 2001) had reported the incidence of various associated injuries in up to $5 \%$ of children with supracondylar fractures, ranging from forearm fractures, clavicle fractures, proximal humerus fractures and physical injuries to the distal radius.

Majority $(80 \%, n=128)$ of children were received in our hospital within 24 hours of sustaining the fracture while $28(17.7 \%)$ in 24 to 48 hours and $4(2.5 \%)$ children were received in 48 to 72 hours of sustaining the fracture. Delayed presented children $(2.5 \%, n=4)$ were initially treated with splints by traditional bone setters but no complication was noted. Usually our hospital received many children who had been initially treated by local bone setters, and even a few with complications like compartment syndrome and gangrene as a result of improper treatment. However during COVID-19 lock down people were only allowed to travel to hospitals which could be the possible explanation of only few cases being treated by bone setters. Anjum et al. (2017) reported that $39.9 \%$ of children in their study were received in hospital within 48 hours after sustaining the injury and they had not been treated by local bone setters, while $60 \%$ children reported after 48 hours and mostly were managed by bone setters initially. In developing countries of Asia and Africa traditional bone setters are more prevalent (Nwachukwu et al. 2011). Omololu et al. (2008) and Onuminya (2006) had documented that in rural areas more than $70 \%$ of skeletal injuries were initially treated by local traditional bone setters. Arora et al. (2008) had reported that more than 70,000 traditional bone setters are treating people in India alone. The usual reasons to consult these bone setters instead of qualified doctors or hospitals were superstitious beliefs, illiteracy, fear of surgery and inability to afford hospital cost (Nwachukwu et al. 2011).

When we searched the literature for the impact of the COVID-19 pandemic on paediatriac supracondylar fractures, we found variable results in different studies from different countries. Gumina et al. (2020) conducted a retrospective comparative cohort study at Sapienza University of Rome, Italy on the impact of COVID-19 on elbow trauma in children. These authors compared their data of paediatric fractures of the COVID-19 period extending from $8^{\text {th }}$ March 2020 to $8^{\text {th }}$ April 2020 with same but non-COVID period in the previous year (2019). In the non-COVID period, 6 children with elbow fractures were noted while in the COVID-period, 3 children with elbow fractures were documented. These authors observed no school injuries, sports injuries and high-energy injuries in children during the COVID-19 pandemic. Elbow fractures during the COVID-19 pandemic occurred at home due to accidental falls. Similarly, Bram et al. (2020) also reported a significant 2.5 fold reduction of paediatric fractures during the COVID-19 pandemic, but an increase in frequency of fractures occurring at home. Contrary to the above studies, Carkci et al. (2021) documented a statistically significant rise in paediatric supracondylar fractures during COVID-19 than the non-COVID period although overall patients' influx was reduced. Carkci was supported by Hashmi et al. (2020) who also reported a higher frequency of paediatric supracondylar 
fractures during COVID-19 than non-COVID period, but the difference was not statistically significant $(\mathrm{P}=0.63)$ in his study. Nabian et al. (2020) noted that paediatric supracondylar fracture was the third-most common fracture presented during COVID-19 after distal radius and radius ulna fracture. Oguzkaya et al. (2021) studied the impact of COVID-19 on the epidemiology of 67 paediatric fractures and noted that the most frequent indication for surgery during COVID-19 was the paediatric supracondylar fracture.

Our study had few limitations. The design of our study was descriptive and we were not able to measure the resilience of the impact absorbing surfaces beneath furniture or play equipment ( $\mathrm{g}$ max). The exact correlation between falling height and impacting surfaces could not be determined. Moreover, indoor playing activities of children vary due to socioeconomic and cultural differences and our results might not be generalized directly for other areas or countries. We suggest further large-scale, well-designed studies to address these limitations and confirm our results.

\section{Conclusion}

Currently no other study exists which assessed the temporal variations and mechanisms of paediatric supracondylar fractures presenting to the hospital during the COVID-19 pandemic. Our study demonstrated that the majority of children sustained fractures due to falls from furniture and landing on hard cemented or tiled surfaces at home. Maximum number of fractures was reported in the month of April and on Monday. Most of these fractures occurred in the evening and were operated on at night. The increased frequency of paediatric supracondylar fractures in the COVID-19 pandemic supports that preventative strategies should focus more on adult supervision, prevention of falls from furniture and provision of softer landing surfaces to lessen the impact of injury. For optimum care of these fractures, dedicated night operation theatres with trained staff are mandatory.

\section{References}

Aktekin CN, Toprak A, Ozturk AM, Altay M, Ozkurt B, Tabak AY (2008) Open reduction via posterior triceps sparing approach in comparison with closed treatment of posteromedial displaced Gartland type III supracondylar humerus fractures. Journal of Paediatric Orthopedics B 17(4): 171-178.

Anjum R, Sharma V, Jindal R, Singh TP, Rathee N (2017). Epidemiologic pattern of paediatric supracondylar fractures of humerus in a teaching hospital of rural India: a prospective study of 263 cases. Chinese Journal of Traumatology 20(3): 158-160.

Aparicio Martinez JL, Pino Almero L, Ortiz de Anda RM, Guillen Botaya E, Garcia Montolio M, Minguez Rey MF (2019) Epidemiological study on supracondylar fractures of distal humerus in pediatric patients. Revista Española de Cirugía Ortopédica y Traumatología (English Edition) 63(6): 394-399.

Arora A, Agarwal A, Gikas P (2008) Musculoskeletal training for orthopaedists and nonorthopaedists: experiences in India. Clinical Orthopaedics and Related Research 466(10): 2350-2359. 
Babal JC, Mehlman CT, Klein G (2010) Nerve injuries associated with pediatric supracondylar humeral fractures: a meta-analysis. Journal of Pediatric Orthopedics 30(3): 253-263.

Barr LV (2014) Paediatric supracondylar humeral fractures: epidemiology, mechanisms and incidence during school holidays. Journal of Children's Orthopaedics 8(2): 167170.

Bianchi ML (2007) Osteoporosis in children and adolescents. Bone 41(4): 486-495.

Bram JT, Johnson MA, Magee LC, Mehta NN, Fazal FZ, Baldwin KD, et al (2020) Where have all the fractures gone? The epidemiology of pediatric fractures during the COVID-19 pandemic. Journal of Pediatric Orthopedics 40(8): 373-379.

Campbell CC, Waters PM, Emans JB (1995) Neurovascular injury and displacement in type III supracondylar humerus fractures. Journal of Pediatric Orthopedics 15(1): $47-52$.

Canales-Zamora OA, Mora-Rios FG, Mejia-Rohenes LC, Anaya-Morales A, GonzalezGijon OR, Lopez-Hernandez JR (2020) Complications of supracondylar humeral fractures in children. Acta Ortopedica Mexicana 34(2): 91-95.

Carkci E, Polat B, Polat A, Peker B, Ozturkmen Y (2021) The effect of the coronavirus 2019 (COVID-19) pandemic on the number and characteristics of orthopedic trauma patients in a tertiary care hospital in Istanbul. Cureus 13(1): 125-32.

Chai KK, Aik S, Sengupta S (2000) Supracondylar fractures of the humerus in children An epidemiological study of 132 consecutive cases. The Medical Journal of Malaysia 55(Suppl. C): 39-43.

Cheng JC, Lam TP, Maffulli N (2001) Epidemiological features of supracondylar fractures of the humerus in Chinese children. Journal of Pediatric Orthopedics B 10(1): 63-67.

Cramer KE, Devito D, Green N (1992) Comparison of closed reduction and percutaneous pinning versus open reduction and percutaneous pinning indisplaced supracondylar fractures of the humerus in children. Journal of Orthopaedic Trauma 6(4): 407-412.

Della-Giustina K, Della-Giustina DA (1999) Emergency department evaluation and treatment of pediatric orthopedic injuries. Emergency Medicine Clinics of North America 17(4): 895-922.

Fiissel D, Pattison G, Howard A (2005) Severity of playground fractures: play equipment versus standing height falls. Injury Prevention 11(6): 337-339.

Gartland JJ (1959) Management of supracondylar fractures of the humerus in children. Surgery, Gynecology and Obstetrics 109(2): 145-154.

Goulding A (2007) Risk factors for fractures in normally active children and adolescents. Medicine and Sport Science 51(Feb): 102-120.

Gumina S, Proietti R, Villani C, Carbone S, Candela V (2020) The impact of COVID-19 on shoulder and elbow trauma in a skeletally immature population: an Italian survey. JSES International 5(1): 3-8.

Gupta N, Kay RM, Leitch K, Femino JD, Tolo VT, Skaggs DL (2004) Effect of surgical delay on perioperative complications and need for open reduction in supracondylar humerus fractures in children. Journal of Pediatric Orthopaedics 24(3): 245-248.

Hallal P, Siqueira F, Menezes A, Araujo C, Norris S, Victora C (2009) The role of early life variables on the risk of fractures from birth to early adolescence: a prospective birth cohort study. Osteoporosis International 20(11): 1873-1879.

Hashmi PM, Marij Z, Ali A, Naqi H, Pidani AS, Hashmi AP, et al (2020) Change in the spectrum of orthopedic trauma: effects of COVID-19 pandemic in a developing nation during the upsurge; a cross-sectional study. Annals of Medicine and Surgery 60(Dec): 504-508. 
Helenius I, Lamberg TS, Kaariainen S, Impinen A, Pakarinen MP (2009) Operative treatment of fractures in children is increasing. A population-based study from Finland. The Journal of Bone and Joint Surgery 91(11): 2612-2616

Houshian S, Mehdi B, Larsen MS (2001) The epidemiology of elbow fracture in children: Analysis of 355 fractures, with special reference to supracondylar humerus fractures. Journal of Orthopedic Science 6(4): 312-315.

Howard AW, MacArthur C, Willan A, Rothman L, Moses-McKeag A, MacPherson AK (2005) The effect of safer play equipment on playground injury rates among school children. Canadian Medical Association Journal 172(11): 1443-1446.

Iyengar SR, Hoffinger SA, Townsend DR (1999) Early versus delayed reduction and pinning of type III displaced supracondylar fractures of the humerus in children: a comparative study. Journal of Orthopaedic Trauma 13(1): 51-55.

Khademolhosseini M, Abd Rashid AH, Ibrahim S (2013) Nerve injuries in supracondylar fractures of the humerus in children: is nerve exploration indicated? Journal of Pediatric Orthopedics B 22(2): 123-126.

Khoshbin A, Leroux T, Wasserstein D, Wolfstadt J, Law PW, Mahomed N, et al (2014) The epidemiology of paediatric supracondylar fracture fixation: a population-based study. Injury 45(4): 701-708.

Laforest S, Robitaille Y, Dorval D, Lesage D, Pless B (2000) Severity of fall injuries on sand or grass in playgrounds. Journal of Epidemiology and Community Health 54(6): 475-477.

Laforest S, Robitaille Y, Lesage D, Dorval D (2001) Surface characteristics, equipment height, and the occurrence and severity of playground injuries. Injury Prevention 7(1): $35-40$.

Latif A (2020, March 18) Pakistan confirms 2 deaths from coronavirus. Anadolu Agency. Retrieved from: https://www.aa.com.tr/en/asia-pacific/pakistan-confirms-2-deaths -from-coronavirus/1771081. [Accessed 18 March 2020]

Lee SH, Kim HW, Song KS (2007) Upper extremity fractures in children e prospective epidemiological study of tertiary medical institutes. Journal of Korean Orthopaedic Association 42(2): 270-275.

LiBrizzi CL, Klyce W, Ibaseta A, Shannon C, Lee RJ (2020) Sex-based differences in pediatric supracondylar humerus fractures. Medicine (Baltimore) 99(20): 267-270.

Loder RT, Krodel E, D'Amico K (2012) Temporal variation in pediatric supracondylar humerus fractures requiring surgical intervention. Journal of Children's Orthopaedics 6(5): 419-425.

Mangwani J, Nadarajah R, Paterson JMH (2006) Supracondylar humeral fractures in children: Ten years' experience in a teaching hospital. Journal of Bone and Joint Surgery $\mathrm{Br}$ 88(3): 362-365.

Marquis CP, Cheung G, Dwyer JSM, Fredrick D, Emery G (2008) Supracondylar fractures of the humerus. Current Orthopaedics 22(1): 62-69.

Mazda K, Boggione C, Fitoussi F, Pennecot GF (2001) Systematic pinning of displaced extension-type supracondylar fractures of the humerus in children. Journal of Bone and Joint Surgery Br 83-B(6): 888-893.

McRae B, Nusem I (2018) Temporal characteristics of paediatric supracondylar humerus fractures. Trauma 20(3): 208-216.

Mehlman CT, Strub WM, Roy DR, Wall EJ, Crawford AH (2001) The effect of surgical timing on the perioperative complications of treatment of supracondylar humeral fractures in children. Journal of Bone and Joint Surgery Am 83-A(3): 323-327.

Milbrandt TA, Copley LAB (2004) Common elbow injuries in children: evaluation, treatment, and clinical outcomes. Current Opinion in Orthopaedics 15(4): 286-294. 
Mulpuri K, Hosalkar H, Howard A (2012) AAOS clinical practice guideline: the treatment of pediatric supracondylar humerus fractures. The Journal of the American Academy of Orthopaedic Surgeons 20(5): 328-330.

Nabian MH, Vosoughi F, Najafi F, Khabiri SS, Nafisi M, Veisi J, et al (2020) Epidemiological pattern of pediatric trauma in COVID-19 outbreak: data from a tertiary trauma center in Iran. Injury 51(12): 2811-2815.

Nwachukwu BU, Okwesili IC, Harris MB (2011). Traditional bonesetters and contemporary orthopedic fracture care in a developing nation: historical aspects, contemporary status and future directions. The Open Orthopaedics Journal 5(1): 20-26.

Oguzkaya S, Misir A, Ozcamdalli M, Eken G, Kizkapan TB, Kurk MB, et al. (2021) Impact of the COVID-19 pandemic on orthopedic fracture characteristics in three hospitals in Turkey: a multi-center epidemiological study. Joint Diseases and Related Surgery 32(2): 323-332.

Okubo H, Nakasone M, Kinjo M, Onaka K, Futenma C, Kanaya F (2019) Epidemiology of paediatric elbow fractures: a retrospective multi-centre study of 488 fractures. Journal of Children's Orthopaedics 13(5): 516-521.

Omid R, Choi PD, Skaggs DL (2008) Supracondylar humeral fractures in children. Journal of Bone and Joint Surgery Am 90-A(5): 1121-1132.

Omololu AB, Ogunlade SO, Gopaldasani VK (2008) The practice of traditional bonesetting: training algorithm. Clinical Orthopaedics and Related Research 466(10): 2392-2398.

Onuminya JE (2006) Performance of a trained traditional bonesetter in primary fracture care. South African Medical Journal 96(4): 320-322.

Ottolenghi CE (1956) Supracondylar fractures of the elbow in children; acute ischemic syndrome: its treatment; prevention of Volkmann's contracture. Prensa Medica Argentina 43(33): 2473-2486.

Ozkoc G, Gonc U, Kayaalp A, Teker K, Peker TT (2004) Displaced supracondylar humeral fractures in children: open reduction vs. closed reduction and pinning. Archives of Orthopaedic and Trauma Surgery 124(8): 547-551.

Park MJ, Baldwin K, Weiss-Laxer N, Christian JB, Mello MJ, Eberson C, et al (2010) Composite playground safety measure to correlate the rate of supracondylar humerus fractures with safety: an ecologic study. Journal of Pediatric Orthopaedics 30(2): 101-105.

Ricci WM, Gallagher B, Brandt A, Schwappach J, Tucker M, Leighton R (2009) Is afterhours orthopedic surgery associated with adverse outcomes? A prospective comparative study. Journal of Bone and Joint Surgery Am 91(9): 2067-2072.

Roposch A, Reis M, Molina M (2001) Supracondylar fractures of the humerus associated with ipsilateral forearm fractures in children: a report of forty-seven cases. Journal of Pediatric Orthopaedics 21(3): 307-312.

Roseveare CA, Brown JM, Barclay McIntosh JM, Chalmers DJ (1999) An intervention to reduce playground equipment hazards. Injury Prevention 5(2): 124-128.

Sacks JJ, Brantley MD, Holmgreen P, Rochat RW (1992) Evaluation of an intervention to reduce playground hazards in Atlanta child-care centers. American Journal of Public Health 82(3): 429-431.

Salonen A, Pajulo O, Lahdes-Vasama T, Valipakka J, Mattila V (2013) Increased incidence of distal humeral fractures and surgical treatment in 0-to 18-year-old patients treated in Finland from 1987 to 2010. Journal of Children's Orthopaedics 7(6): 559-564.

Sibinski M, Sharma H, Bennet GC (2006) Early versus delayed treatment of extension type-3 supracondylar fractures of the humerus in children. Journal of Bone and Joint Surgery $\mathrm{Br}$ 88(3): 380-381. 
Sinikumpu J, Pokka T, Sirvio M, Serlo W (2016) Gartland type-II fractures, their operative treatment and lateral pinning are increasing. A population-based epidemiologic study of extension type supracondylar humerus fractures in children. European Journal of Pediatric Surgery 27(5): 455-461.

Sinikumpu J, Pokka T, Hyvonen H, Ruuhela R, Serlo W (2017) Supracondylar humerus fractures in children: the effect of weather conditions on their risk. European Journal of Orthopaedic Surgery \& Traumatology 27(2): 243-250.

Sinikumpu J, Victorzon S, Pokka T, Lindholm E, Peljo T, Serlo W (2016) The long-term outcome of childhood supracondylar humeral fractures. The Bone \& Joint Journal 98-B(10): 1410-1417.

Skaggs DL, Flynn JF (2010) Supracondylar fracture of the distal humerus. In JH Beaty, JR Kasser JR, (eds.), Rockwood and Wilkins' Fractures in Children, 487-531. 7th Edition. Philadelphia: Lippincott William and Wilkins.

Strait RT, Siegel RM, Shapiro RA (1995) Humeral fractures without obvious etiologies in children less than 3 years of age: when is it abuse? Pediatrics 96(4): 667-671.

Striano BM, De Mattos C, Ramski DE, Flynn KR, Horn BD (2020) Displaced supracondylar humerus fractures in toddlers. Orthopedics 43(5): 421-424.

Turhan E, Aksoy C, Ege A, Bayar A, Keser S, Alpaslan M (2008) Sagittal plane analysis of the open and closed methods in children with displaced supracondylar fractures of the humerus (a radiological study). Archives of Orthopaedic and Trauma Surgery 128(7): 739-744.

Wareham K, Johansen A, Stone MD, Saunders J, Jones S, Lyons RA (2003) Seasonal variation in the incidence of wrist and forearm fractures, and its consequences. Injury-International Journal of the Care of the Injured 34(3): 219-222.

Woratanarat P, Angsanuntsukh C, Rattanasiri S, Attia J, Woratanarat T, Thakkinstian A (2012) Meta-analysis of pinning in supracondylar fracture of the humerus in children. Journal of Orthopaedic Trauma 26(1): 48-53. 
